\title{
SURDEZ E EDUCAÇÃO INFANTIL: OS DESAFIOS PARA A PROPOSTA EDUCACIONAL BILÍNGUE NO MUNICÍPIO DE TRÊS LAGOAS, MATO GROSSO DO SUL
}

\author{
Deafness and early childhood education: the challenges for bilingual education \\ proposal in Três Lagoas, Mato Grosso do Sul
}

\author{
Sordera y educación de la primera infancia: los retos de la propuesta de educación \\ bilingüe en Três Lagoas, Mato Grosso do Sul
}

Sheyla Cristina Araujo Matoso Silva ${ }^{1}$

\begin{abstract}
Resumo
Este artigo visa a discutir a atual proposta educacional para alunos surdos na etapa da educação infantil, evidenciando as necessidades mais latentes das crianças surdas inseridas na etapa inicial do ensino comum. Vale ressaltar que essa etapa de escolarização é considerada como base de desenvolvimento para as demais vindouras, no entanto, quando é experimentada por crianças surdas, as diretrizes que contribuem para seu desenvolvimento nem sempre são claras, dentre elas, o acesso à língua de sinais, fator extremamente importante no que diz respeito à aceitação das diversidades, inclusive as linguísticas. A pesquisa foi realizada em instituições públicas que atendem a essa etapa inicial da educação de alunos surdos no município de Três Lagoas, Mato Grosso do Sul e, por meio de levantamento de dados, foram encontradas apenas duas crianças surdas matriculadas nessas instituições. Dentre outros aspectos, observamos, também, que os profissionais envolvidos no processo em questão ainda desconhecem os principais pontos de uma proposta educacional bilíngue. Pretendemos, sobretudo, ressaltar a importância de se discutir as propostas educacionais para os surdos, desde os primeiros anos escolares, no intuito de atender a tão almejada educação bilíngue.
\end{abstract}

PALAVRAS-CHAVE: Educação Infantil. Crianças surdas. Educação Bilíngue

\begin{abstract}
The aim of this article is to discuss the current educational proposal for deaf students in early childhood education in order to highlight the most latent needs of deaf children in their initial stage of regular education. We stress that this stage of schooling is regarded as a basis for development of the forthcoming stages, however, when it is experienced by deaf children, the guidelines that contribute to their development are not always clear, such as the access to sign language, which is an extremely important factor in the acceptance of diversities, including the linguistic ones. The research was carried out in public educational institutions that cater to deaf students in their initial stage of education in Três Lagoas, Mato Grosso do Sul, and by means of data collection, we found only two deaf children enrolled in such public educational institutions. It is noteworthy that the professionals involved in this process are still unaware of the main points of a bilingual educational proposal. We intend, above all, to point out the importance of discussing the educational proposals for deaf people since the early school years in order to achieve the coveted bilingual education.
\end{abstract}

\footnotetext{
${ }^{1}$ Pedagoga, Mestre em Educação pela Universidade Estadual de Mato Grosso do Sul, professora de Língua Brasileira de Sinais na Universidade Federal de Mato Grosso do Sul, Campus Três Lagoas. Endereço Postal Rua João Silva, 545, Centro, Três Lagoas. E-mail: smatosos@ hotmail.com.
} 
KEYWORDS: Early Childhood Education. Deaf children. Bilingual Education

\section{Resumen}

El objetivo del presente estudio es analizar la propuesta educativa actual para los estudiantes sordo sem la etapa de Educación Infantil, que apunta a las necesidades más latentes de los niños sordos introducidos em el paso educación inicial común. Se sabe que el paso de la inscripción es considerado como una base para el desarrollo de otros futuro, sin embargo, cuando es experimentado por los niños sordos no siempre profesionales y claridad de los elementos que contribuyen al desarrollo de estos niños, entre los que se destaca este acceso a la investigación para ell enguaje de señas, factor extremadamente importante cuando se habla de la aceptación de la diversidad, entre ello sel idioma. La encuesta se llevó a cabo em las instituciones públicas que atienden a paso indicado en este tema en Três Lagoas, Mato Grosso do Sul. Através de la recopilación de datos, se encuentra a sólo dos niños sordos matriculados em las instituciones de investigación citados. Entre otros aspectos destacados, se observa que los profesionales que intervienen em el proceso em cuestión todavía no son conscientes de los puntos principales de una propuesta educativa bilingüe. Es de destacar también que esta investigación pretende hacer hincapiéen la importancia de discutir las propuestas educativas para sordos, a partir de los primeros años de escuela com el fin de cumplir com la educación bilíngüe codiciado.

PALABRAS CLAVE: Educación para la Primera Infancia. Los niños sordos. Educación Bilingüe

\section{INTRODUÇÃO}

Com o advindo da proclamação do respeito à diversidade e da proposta de inclusão escolar ${ }^{2}$, aos surdos foi destinada a matrícula no ensino comum e o direito de ter sua escolarização em sua língua oficializada ${ }^{3}$ no país. Por meio da anunciação desses direitos no início deste novo século, a educação de surdos passa por mudanças e estes têm seu ensino assegurado por uma vertente bem diferente da anterior ${ }^{4}$, esses alunos têm, agora, o direito de serem ensinados por meio da Libras e de contar com alguns novos profissionais que terão a função de colaborar com o processo de ensino e aprendizagem destes alunos.

Inicia-se um cenário diferente na escola, e essa passa a receber em suas matrículas aquele aluno que utiliza uma outra língua que não seja a Língua Portuguesa, além de necessitar de outros ajustes que contemplem um ensino no qual a Língua Portuguesa tem função de segunda língua e não mais de primeira.

Essas crianças, que antes eram mantidas em instituições especializadas passam a chegar cada vez mais cedo às escolas e alcançam a etapa da educação infantil. Essa etapa tem em seu histórico um processo semelhante, no que tange a ressignificação, uma vez que, atualmente, a educação infantil como a etapa inicial da educação básica, é regida pelas

\footnotetext{
${ }^{2}$ Optou-se pela terminologia "inclusão escolar" levando em conta as discussões de Bueno (2008) onde o autor analisa o processo inter-relação entre a educação especial e a educação inclusiva, problematizando inclusive as traduções dos documentos legais internacionais, e indica que o conhecimento dos conceitos é fundamental para as discussões acerca do tema.

${ }^{3}$ No Brasil a Libras foi oficializada como língua utilizada pelos surdos brasileiros no ano de 2002, através da Lei 10.436 (BRASIL, 2002).

${ }^{4}$ Por um período de aproximadamente cem anos os surdos eram proibidos de se comunicarem por meio da língua de sinais e a escola tinha a função de atender o processo de oralização e normalização dos surdos.
} 
políticas públicas elaboradas para garantir o acesso e desenvolvimento das crianças, especialmente, as de zero a cinco anos ${ }^{5}$.

No entanto, apesar de todo o aparato legal, que garante à criança seu direito de matrícula na etapa da educação infantil, bem como em outras etapas escolares, e o ensino bilíngue $^{6}$ em todas as etapas, observa-se que urge a necessidade de pesquisas que contemplem e explanem os direcionamentos relacionados à criança surda incluída na educação infantil.

Este estudo, portanto, visa a discutir a inclusão escolar de crianças surdas na etapa da educação infantil nas instituições municipais do município de Três Lagoas, Mato Grosso do Sul. Optou-se por este viés de análise pelo fato de se observar discursos sobre a educação infantil em relação à criança não precisar conhecer, nem ser fluente na língua de sinais ou necessitar de atividades muito elaboradas, uma vez que essa etapa era compreendida como uma etapa de pouca importância, pois, nessa visão, as crianças só precisavam brincar e ter os cuidados de higiene pessoal. Assim como para as demais crianças, o desenvolvimento nos primeiros anos de vida é fundamental para a criança surda para a constituição da linguagem, a qual estabelecerá as diversas ligações e ajustes afetivos emocionais e intelectuais.

Mendes (2010, p. 47) ressalta que:

Os primeiros anos de vida de uma criança têm sido considerados cada vez mais importantes. Os três primeiros anos, por exemplo, são críticos para o desenvolvimento da inteligência, da personalidade, da linguagem, da socialização, etc. A aceleração do desenvolvimento cerebral durante o primeiro ano de vida é mais rápida e mais extensiva do que qualquer outra etapa da vida $[\ldots]$.

Nesse sentido, os primeiros anos de vida de uma criança são extremamente dependentes de seus familiares e/ou cuidadores. No caso da criança com deficiência não é diferente; a dependência dela e a intervenção de um adulto são fatores indiscutíveis, e a estimulação necessária para seu crescimento e desenvolvimento serão também fundamentais, assim como para as crianças sem deficiência.

Para Drago (2011, p. 147), “[...] ao se conceber a inclusão como um processo meramente socializador, corre-se o risco de se perder de vista o caráter maior da educação [...] da Educação Infantil como primeira etapa da Educação Básica também para a criança deficiente". Consoante a essa postura, é preciso pensar na educação infantil como etapa inicial da educação, e não apenas no quesito de socialização, como ocorre algumas vezes quando se refere aos alunos com deficiência.

No entanto, pode-se pontuar que o acesso ao ensino comum, desde os primeiros anos, não é o que garante sua aceitação, tampouco garante o ensino pautado em ações educativas engajadas nessa ideia de novos caminhos para alcançar os objetivos traçados.

\footnotetext{
${ }^{5}$ Apesar de encontrar nos regimentos legais indicativos de um atendimento na etapa da Educação Infantil de zero a seis anos, a mudança do ensino fundamental para nove anos antecipou a entrada das crianças no ensino fundamental, e, com isso, as crianças permanecem na primeira etapa até os cinco anos e não mais até os seis anos. Tal alteração é proveniente das discussões sobre o tema e está em vigor desde 2005, ano em que a Lei $n^{\circ} 11.114$ entrou em vigor alterando os artigos $6^{\circ}, 30,32$ e 87 da Lei no 9.394/1996 (BRASIL, 2005a).

${ }^{6}$ Entende-se por ensino bilíngue o modelo em que a Libras - Língua Brasileira de Sinais é tratada como a primeira língua dentro do processo de ensino para surdos e a Língua Portuguesa na modalidade escrita constitui segunda língua. $\mathrm{O}$ ensino da fala é compreendido como opcional nessa perspectiva bilíngue (BRASIL, 2005b).
} 
Dentre esses caminhos, ressaltam-se estratégias precocemente pensadas para o desenvolvimento das crianças que necessitam de algum direcionamento específico.

Dentre os procedimentos metodológicos adotados neste estudo, houve, em princípio, a necessidade de conhecer e interagir com o público alvo da pesquisa, o que exigiu uma busca pela realidade local, ou seja, contextualizar a etapa da educação infantil nas instituições públicas do município de Três Lagoas com base na demanda atual da população três-lagoense.

Ao final da busca quantitativa chegamos aos sujeitos que seriam parte principal nessa investigação, duas crianças com surdez profunda, denominadas nesta pesquisa como A1- uma criança com três anos de idade, matriculada no Centro de Educação Infantil- CEI; e A2- uma criança com cinco anos de idade, matriculada em uma sala de Pré I de uma escola regular.

Observou-se que, para o aluno A2, foi contratada uma Tradutora e Intérprete de Língua de Sinais- TILS, com a qual foi realizada uma entrevista focalizada, no intuito de investigar a relação do aluno com a língua de sinais e o seu atendimento na escola pelo olhar da TILS, tendo como norte que esse profissional tem importante função em todo o processo educativo dos alunos aqui apresentados.

Já o aluno matriculado no CEI, denominado A1, não havia esse profissional para seu apoio. No entanto, foi contratada uma estagiária como auxiliar da professora, que ficava responsável em ajudar a criança nas atividades, mas esta não possuía nenhum conhecimento em LIBRAS. A informação fornecida pela responsável na SEMED é que seguiriam o ano com a contratação de um TILS, fato esse que apontava contradições com o previsto no Decreto $\mathrm{n}^{\circ} 5.626$ (BRASIL, 2005b). O referido Decreto não proíbe a contratação do intérprete, mas prevê, entre outros direcionamentos, o professor bilíngue para a etapa da Educação Infantil e primeiros anos do ensino fundamental, e não o TILS, conforme o artigo 22, inciso I, as instituições devem ser planejadas de forma que assegure: "[...] escolas e classes de educação bilíngüe, abertas a alunos surdos e ouvintes, com professores bilíngües, na educação infantil e nos anos iniciais do ensino fundamental" (BRASIL, 2005b).

Cabe ressaltar que um dos fatores que torna difícil essa contratação é a escassez de profissionais habilitados nesse quesito bilíngue ${ }^{7}$, mesmo havendo uma disciplina obrigatória de Libras nos cursos de formação de professores, apontado pelo Decreto 5.626 (BRASIL, 2005), cuja carga horária disponibilizada para cada licenciatura não é condizente com os processos de formação bilíngue, tornando tal disciplina insuficiente para esse profissional.

\section{Referencial teórico}

É importante observar que a formação de professores bilíngues para atender os níveis iniciais de escolarização é uma das estratégias apontadas no relatório ${ }^{8}$ sobre a política linguística de educação bilíngue - Língua Brasileira de Sinais e Língua Portuguesa e, acerca da formação inicial e continuada dos profissionais envolvidos no processo de escolarização dos alunos surdos, o documento indica:

\footnotetext{
${ }^{7}$ Compreende-se por professor bilíngue o professor que seja fluente nas duas línguas, Libras e Língua Portuguesa.

${ }^{8}$ Tal relatório foi elaborado pelo grupo de trabalho sobre políticas linguísticas e indica possibilidades para constituir os espaços educativos na tentativa de se concretizar a propostade um ensino bilíngue para os alunos surdos.
} 
Os cursos de graduação envolvem a Pedagogia Bilíngue (que forma o professor bilíngue de atuar na educação infantil e séries iniciais do ensino fundamental), os cursos de Letras Libras licenciatura (que forma professores de Libras para atuar no ensino da Libras na educação básica e nível médio) e bacharelado (que forma tradutores e intérpretes de Libras e Língua Portuguesa). O Curso de Língua Portuguesa como L2 deve ser oferecido para formar os professores que atuarão, tanto na educação básica, como no nível superior. (BRASIL, 2014, p. 17)

No entanto ainda presenciamos quadros onde a comunicação entre os professores ouvintes e os alunos surdos não acontecer de forma tranquila, exatamente pela falta de domínio das línguas envolvidas, torna esse processo de inclusão ainda mais confuso e desastroso. E o aluno surdo carrega consigo estereótipos como os apresentados no depoimento da P1 e possivelmente outros que não foram citados, tendo em vista sua dificuldade em se socializar com os demais pela falta de uma língua, seja a de sinais ou a oralizada.

Para Rabelo (2012, p. 240),

Neste contexto, é questionável a exequibilidade de uma proposta de inclusão escolar num contexto de uma sociedade capitalista essencialmente excludente. Para uma análise mais apurada é necessário relacionar práticas sociais e culturais construídas historicamente para estigmatizar pessoas consideradas 'desviantes' da norma, aqui no caso em debate, pessoas com deficiência.

Lima (2011, p. 161) adverte que,

\begin{abstract}
Ao analisar as várias implicações que decorrem da inclusão de surdos na escola regular, Perlin e Quadros (1997) destacam as implicações linguísticas, que dizem respeito ao descumprimento dos direitos de os surdos terem acesso ao conhecimento através da sua própria língua (língua de sinais, que se constitui primeira língua- L1) e, também, ao conflito de necessidades entre surdos e ouvintes com relação à língua portuguesa, considerada primeira língua para os ouvintes e segunda para os surdos (L2). Portanto, acreditamos que se não forem consideradas e respeitadas as particularidades dos surdos no tocante à sua principal idiossincrasia, a língua de sinais, haverá dificuldades em se promover um verdadeiro processo inclusivo.
\end{abstract}

Nesse sentido, discutiu-se que esse respeito linguístico deve se iniciar nos primeiros anos de vida, quando a linguagem já deve fazer parte do contexto da criança a partir de suas interações sociais, das mais diversas possíveis. Com isso, a diferença linguística entre surdos e ouvintes não pode ser o limitante, e sim se tornar propulsora de novos elementos construtivos.

Para Lacerda (2009, p. 27), "Não basta um decreto para uma transformação efetiva das práticas. A legislação pode induzir ações, mas elas só serão eficazes se de fato a condição linguística especial do surdo for compreendida e ações para a criação de uma efetiva escola bilíngue forem implementadas".

Quadros (1998), discutindo sobre a aquisição da LIBRAS por crianças surdas, apresenta uma pesquisa feita por Bellugi e Petitto (1988) referente à aquisição da Língua de Sinais Americana (ASL) por crianças surdas americanas em que revela:

Os dados sugerem que a criança surda de nascença, com acesso a uma língua espaço-visual proporcionada por pais surdos, desenvolverá uma linguagem sem qualquer deficiência. Além disso, os dados apresentados sugerem que os fundamentos da linguagem não estão baseados na forma do sinal, mas, sim na 
função linguística que a serve. [...] Esse processo ocorre em período análogo à aquisição de crianças ouvintes. (QUADROS, 1998, p. 78).

E, ainda, com relação à outra pesquisa semelhante, que:

Outro estudo realizado com surdos adultos que adquiriram a língua de sinais em diferentes fases da vida, [...] apresentou resultados que sugerem que realmente existe um período adequado para o aprendizado da língua. Ou seja, a aquisição da linguagem é muito melhor quando realizada o mais precocemente possível. (QUADROS, 1998, p. 79).

Tal pesquisa confere de maneira análoga com a pesquisa feita pela própria Quadros (1995) com crianças surdas brasileiras, a qual também demonstra a importância da aquisição precoce da língua para o pleno desenvolvimento nos aspectos cognitivos, emotivos e sociais.

Ainda sobre a aquisição da linguagem pelas crianças surdas as falas das entrevistadas P1 e $\mathrm{C} 1$, demonstram a realidade local das instituições pesquisadas no que tange aos encaminhamentos para a interação do surdo com a língua de sinais, deixando explícitos que ainda não são contemplados para atender o que aponta o relatório já citado, elaborado pelo grupo de trabalho que explana a questão da educação bilíngue:

A Educação Bilíngue de surdos envolve a criação de ambientes linguísticos para a aquisição da Libras como primeira língua (L1) por crianças surdas, no tempo de desenvolvimento linguístico esperado e similar ao das crianças ouvintes, e a aquisição do português como segunda língua (L2). (BRASIL, 2014, p. 6).

\section{Discussões e análise dos dados coletados na pesquisa}

Com relação à língua de sinais e à criança surda, a professora P1 explana que ela nem a atendente têm conhecimento da língua, e que se a criança utilizasse a língua, elas não estariam preparadas para atendê-la. A professora descreve com detalhes como direciona as atividades:

[...]a linguagem de sinais não, mesmo porque eu não estou preparada, nem a atendente; não estamos preparadas pra isso, certo? O que a gente faz é a mesma linguagem que eu utilizo a linguagem oral com as outras crianças eu utilizo com ele, por ele possuir essa deficiência, eu procuro, as vezes ... a gente usa os métodos que tem. Fala um pouco mais alto, próximo dele entendeu? Então toda a atividade que eu vou fazer, eu procuro trazer ele mais próximo de mim ... fala mais alto, mostra pra ele, né, com gestos pra que de alguma maneira ele possa participar, aprender. (ENTREVISTADA: P1).

Percebe-se que as orientações sobre o atendimento de crianças surdas nessa etapa não são concebidas de maneira satisfatória nessa instituição, não por desinteresse dos profissionais envolvidos, mas por concepções equivocadas de se compreender o que e como seria a educação bilíngue assegurada às crianças surdas. Para elucidar isso, são citados os direcionamentos descritos no artigo 22 do capítulo VI, inciso I, do Decreto $\mathrm{n}^{\mathrm{o}}$ 5.626 (BRASIL, 2005b), que, conforme apresentados nos capítulos anteriores, definem o perfil dos professores que as instituições devem prever para atenderem as crianças surdas na etapa da educação infantil: "I - escolas e classes de educação bilíngüe, abertas a alunos surdos e ouvintes, com professores bilíngües, na educação infantil e nos anos iniciais do ensino fundamental" (BRASIL, 2005b). 
Lacerda (2012, p. 278) discutindo a educação de surdos e seus componentes destaca que "[...] Na medida em que a condição linguística especial do surdo é respeitada, aumentam as chances de ele se desenvolver e construir novos conhecimentos de maneira satisfatória, em contraponto a uma inclusão escolar sem qualquer cuidado especial".

Com o intuito de esclarecer alguns pontos sobre a proposta educacional bilíngue, é que menciona-se o "Relatório sobre a Política Linguística de Educação Bilíngue - Língua Brasileira de Sinais e Língua Portuguesa" (BRASIL, 2014), constituído neste ano de 2014, pelo grupo de trabalho:

No contexto da educação bilíngue de surdos destaca-se o fato de a maior parte das crianças surdas terem acesso tardio à Libras, o que exige um programa na educação infantil no qual as crianças sejam expostas a interações na Libras precocemente. A partir disso, instaura-se a educação bilíngue contando com a língua de sinais como a língua de instrução, além de compreender disciplina específica de ensino, na qualidade de L1 (ensino de língua materna). (BRASIL, 2014, p. 9).

Dentre as metas citadas no referido Relatório, algumas se referem à etapa da educação infantil, pedindo providências quanto à forma de se organizar a educação bilíngue aos alunos surdos. Uma delas aponta a necessidade de "Criar programas de imersão precoce para aquisição da Libras na educação infantil, com interlocutores fluentes em Libras, prioritariamente surdos" (BRASIL, 2014, p. 19).

Esta pesquisa demonstra que os professores investigados ainda desconhecem os resultados e pressupostos do ensino bilíngue, e, por vezes, não sabem como desenvolver o trabalho na educação infantil para atingir os objetivos propostos pela atual política linguística.

As discussões acerca da inclusão escolar permeiam caminhos que remetem ao pensamento destacado por Oliveira (2008, p. 163),

Se, por um lado, essas posições favoráveis à inclusão de crianças com deficiência na classe do ensino regular representam um avanço em termos do acesso à educação dessa parcela da população de alunos, por outro, vários autores têm apontado em seus estudos que, principalmente nas escolas públicas, têm sido desenvolvidas práticas pedagógicas que não favorecem o êxito escolar de muitos alunos.

Outra observação importante de mencionar são os estigmas presentes, na maioria dos casos, quando se referem à criança com algum tipo de deficiência, o indicativo de que esta acarreta outros aspectos comportamentais e de desenvolvimento. Nesse caso, a professora destaca o comportamento inadequado da criança surda, fazendo uma possível referência desse comportamento a sua deficiência, como segue em um dos trechos da entrevista:

Tem uma atendente específica pra ele que fica junto com ele sabe, orientando nas atividades, cuidando dele porque principalmente de uns dias pra cá ele anda muito inquieto, sabe, ele meche em tudo, certo $i$ eu estava até comentando se é uma fase que ele está passando ou já é em decorrência da deficiência que ele tem que vai deixando ele com essa maneira irritado; ele tá totalmente agitado, ele não para , nós tivemos que subir as coisas, tá vendo ¿ porque se deixar ali ele pega aí ele se distrai facilmente, e ele procura se distrair com essas coisas. Brincar com outros objetos. E eu quero, a gente quer que ele participa, que fica numa roda de conversa, e ele de certa maneira fica sabe a gente em cima dele, ele realiza as atividades que a gente propõe, faz junto com os colegas. (ENTREVISTADA: P1). 
Percebe-se que muitas vezes, essas reações são oriundas de ideias fixadas, durante muito tempo, de que a deficiência traz consigo sempre inadequações que deixam mais latentes seu estado de "anormalidade". No caso das crianças surdas, a falta de uma língua de instrução, e com isso a ausência de uma comunicação efetiva, acarreta, em geral, reações que são condizentes com o fato de não estarem conseguindo entender, por vezes, o que está acontecendo ao seu redor, ou ainda de não serem compreendidas nas tentativas frustradas de comunicação.

Segundo relatos da professora P1, quando inquerida sobre a questão de o aluno ter tido acesso à língua de sinais, ou se houve alguma orientação sobre isso, ela relatou:

Não. Ele não faz ainda; até outro dia teve um pessoal do AEE, umas meninas, conversamos, ela viu ele né... ainda não. Porque ele está em processo de tratamento pra ver se recupera a audição, entendeu? Agora mesmo, em maio ele vai passar por um médico especialista, se possível for uma cirurgia de implante entendeu? Mas assim ... até então não. Mas as meninas comentaram que se ele não vir a ouvir realmente vai ser necessário, sim. Uma forma de comunicação, né. (ENTREVISTADA: P1)

Os anos iniciais de vida da criança surda são importantes para seu desenvolvimento, não apenas linguístico, assim como o é para todas as crianças, e o fato de a própria família não ter orientações precisas de como agir poderá acarretar em consequências que vão além da falta de uma língua propriamente dita. Nesse sentido, o próprio Decreto $\mathrm{n}^{\mathrm{o}} 5.626$ (BRASIL, 2005b) pontua, no artigo 25 do capítulo VII, que se devem dar "[...] orientações à família sobre as implicações da surdez e sobre a importância para a criança com perda auditiva ter, desde seu nascimento, acesso à Libras e à Língua Portuguesa".

Sobre esses primeiros anos de vida, Lodi e Luciano (2010, p.34) destacam que "[...] o desenvolvimento da linguagem, atividade exclusiva dos seres humanos, tem seu início a partir das interações do bebê com as pessoas ao seu redor, por meio das quais ele poderá se apropriar dos aspectos culturais do meio social em que vive". Nesse sentido, tanto os familiares e cuidadores quanto as instituições que recebem as crianças menores precisam ter as orientações para que se possa inserir as crianças surdas em um contexto linguístico aplicável ao uso da LIBRAS como primeira língua.

Outro relato importante é o da coordenadora $\mathrm{C} 2$, que destaca como iniciaram os primeiros contatos do aluno surdo A2 com a LIBRAS, ainda no CEI:

\begin{abstract}
E aí eu vi meu sonho realizado. La no CEI quando ela sentava com ele pra ver o alfabeto do surdo e mudo, né, porque eu não vou falar a criança, mas eu vou falar que é uma grande profissional que é a intérprete. Ela trabalha na rede do estado também, e ela trouxe o alfabeto e ele começou a conhecer, eu arrepio de falar isso... mas isso é o nosso melhor troféu. (ENTREVISTADA: C2).
\end{abstract}

Esses ambientes linguísticos somente serão possíveis quando um número maior de profissionais da educação for fluente em LIBRAS e, ainda, quando houver a contratação dos instrutores surdos, previstos também no Decreto $n^{\circ} 5.626$ (BRASIL, 2005b) e que poderão fazer esse incentivo e interação linguística.

Ainda sobre a questão da aquisição da língua, a intérprete relata como aconteceram as primeiras interações ${ }^{9}$ do aluno A2 com a LIBRAS:

\footnotetext{
${ }^{9}$ Esse acesso inicial não ocorreu na escola e sim no CEI, quando o aluno estava no Maternal III, com a mesma intérprete, conforme relato da coordenadora da escola, já descrito nos parágrafos anteriores desta discussão. Porém, é importante para a pesquisa apresentar como aconteceu esse contato inicial com a língua.
} 


\begin{abstract}
No início quando eu tive contato com ele era mais mímica que ele usava com a mãe dele, nesse caso uma coisa ou outra que ele fazia, mas não... era praticamente insignificante, se você conceber ao aprendizado que uma criança surda e... foi uma experiência boa, porque é... tive a oportunidade de passar aquilo que fosse pelo menos essencial pra comunicação pro início né, sinal de mãe, água, quando ele queria alguma coisa, quando ele queria ir no banheiro né, e ele teve um desenvolvimento assim... bastante considerável, que os professores admirou né, e a... não sei se a autoestima dele mesmo né, ele passou a ter uma socialização melhor com as crianças. (ENTREVISTADA: INTÉRPRETE).
\end{abstract}

Neste caso, percebe-se que a função designada à intérprete, a princípio, não se deteve exatamente à interpretação de uma língua-alvo para uma língua-fonte, e sim para o ensino da língua, uma vez que a criança ainda não era fluente em LIBRAS. A situação relatada é também um ponto a ser discutido, pois se compreende que a língua não deva ser ensinada e sim adquirida de maneira gradual, à medida que as relações vão sendo estabelecidas.

Nesse cenário é que se pode situar o instrutor surdo, também descrito no Decreto $\mathrm{n}^{\circ}$ 5.626 (BRASIL, 2005b), que tem a função de levar as crianças surdas a terem uma maior interação com a língua de sinais, proporcionando momentos de troca linguística em uma primeira língua. Isso para não correr o risco de se pensar nesses momentos como ensino de uma segunda língua, tendo em vista que, para o intérprete de LIBRAS, a língua portuguesa possui caráter de primeira língua, diferentemente dos surdos.

Para Lodi e Luciano (2010, p.48), as crianças surdas vivem em um contexto cujas atividades são pensadas para alunos ouvintes. Os autores destacam:

Mesmo em sala de aula, com a presença do intérprete, as práticas de ensino são aquelas planejadas para ouvintes, o que inviabiliza, pelo atraso de linguagem em que chegam ao espaço escolar, uma maior participação das crianças nas atividades.

A resposta a este questionamento fica na dependência de uma transformação das situações desenvolvidas no espaço escolar, de forma a levar as crianças ao estabelecimento de relações em Libras por um período maior de tempo. (LODI; LUCIANO,2010, p.48).

Ainda quanto ao profissional citado, tradutor-intérprete de língua de sinais, existem alguns equívocos referentes à real função desse profissional dentro dos espaços educativos. Lacerda (2009), trazendo alguns apontamentos observados em uma pesquisa com intérpretes no espaço educativo, ressalta que esses profissionais

[...] assumem diversas funções inclusive de motivadoras dos alunos, para além da tarefa específica de interpretar. Não se trata de ocupar o papel do professor, mas nas relações próximas às crianças surdas é difícil pensar que elas não se sintam (também) responsáveis por bons resultados em sua aprendizagem. Muitos autores defendem que esse profissional deveria integrar a equipe educacional das escolas sendo formados e colaborando para as reflexões que envolvem a aprendizagem dos alunos surdos. (LACERDA, 2009, p. 52).

Em uma das falas da professora $\mathrm{P} 2$, ela explana algumas dessas confusões quanto à maneira mais adequada de direcionar os trabalhos desse profissional:

Agora a questão do intérprete, eu acho importante, mas, eu não concordo que o intérprete fica com a criança dois, três anos. Porque pega afetividade que atrapalha, o vínculo atrapalha, entendeu? Eu acho que não deveria. Eu acho que se você coloca intérprete muito tempo com a criança ela não vê como professor, 
fica muito próximo a afetividade. E intérprete acaba... eu não falo que aconteceu isso comigo, entendeu, eu falo pelos meus amigos, colegas que já reclamaram disso, e aí o intérprete começa a ajudar demais e acaba atrapalhando, entendeu? (ENTREVISTADA: P2).

Lacerda e Bernardino (2010, p. 75), discutindo sobre a importância da etapa inicial de escolarização para atender a condição bilíngue dos alunos surdos, destacam:

A educação infantil tem a responsabilidade de contribuir para o desenvolvimento da linguagem de qualquer criança, mas seu compromisso com a criança surda tem um componente singular em virtude da necessidade de construir a condição bilíngue. [...]. Para essa construção é imprescindível privilegiar a Libras.

Percebe-se que existem ainda muitas incertezas com relação aos profissionais que devem estar inseridos nas instituições que atendam alunos surdos e incertezas no agir pedagógico, construindo espaços que respeitem os aspectos linguísticos próprios dos surdos, bem como as contribuições para que se tenham espaços em que essa diferença linguística seja pensada de maneira mais efetiva.

\section{CONSIDERAÇÕES FINAIS}

Dos resultados obtidos e apresentados neste artigo apontamos que os profissionais envolvidos no processo de inclusão escolar encontram-se em nos depoimentos de ambas as professoras alegações de não estarem preparadas para atenderem os alunos "incluídos" e ainda demonstrações de descontentamento, não com a presença, mas com a maneira como essa inclusão tem acontecido, percebidas nas entrevistas que seguem neste artigo.

Dorziat, Araújo e Soares (2011), ao discutirem uma pesquisa realizada com professores que tinham alunos surdos matriculados em suas salas de aula do ensino comum, destacam que "A maioria desses professores deixam transparecer certa insatisfação face a esse novo processo. Essa insatisfação surge, principalmente, devido à falta de capacitação específica, o que é necessário para possibilitá-los a incluir os alunos surdos de modo eficaz [...]” (DORZIAT; ARAÚJO; SOARES, 2011, p. 52).

Tal insatisfação não é algo único e exclusivo da educação de surdos, mas sim uma insatisfação com as formas e processos mal pensados e, por consequência, mal elaborados quando se referem à inclusão escolar de maneira geral.

Mendes (2010, p. 62) destaca:

Considerando que se encontra legalmente estabelecido o direito dos alunos com necessidades especiais de ingressar nas turmas comuns, inclusive nas creches, seria preciso, portanto, preparar o educador para recebê-los, e esse preparo deveria estar sendo sistematizado nos cursos regulares de formação. Entretanto, a recenticidade das ideias, tanto da proposta de inclusão escolar quanto a ideia das creches fazerem parte do sistema educacional, ainda não permitiu que fosse produzido o conhecimento necessário para se saber como deve ser a formação dos educadores de creches.

O primeiro ponto que se destaca com relação a esta pesquisa refere-se à carência de estudos direcionados à área da inclusão escolar na educação infantil, tanto em estudos mais gerais, quanto sobre a educação de surdos, pois, por meio do levantamento da produção da área, foi possível verificar quão escassa é a produção de materiais e estudos referentes à temática abordada, o que impulsiona a continuidade de estudos e pesquisas relacionadas a ela e tentar, de maneira singular, contribuir nas ações a serem elaboradas para se 
contemplar a educação dos surdos, não apenas em uma ou outra etapa de escolarização, mas em todo o processo educacional.

O fato é que pensar em uma educação que aceite verdadeiramente a todos é preciso, antes de tudo, pensar em mudanças de cunho social e político. Nesse sentido, pontuar que o descaso ocorre somente na etapa em evidência na pesquisa seria um equívoco muito grande, e pensar que as políticas públicas são suficientes para tornar a sociedade mais inclusiva é, com certeza, um equívoco ainda maior. Isso porque tais documentos acabam por expressar os interesses do Estado e a escola, por sua vez, tende a reproduzir o discurso oficial.

Neste sentido, as reflexões de Faria et al. (2011, p. 193) nos apresentam algumas considerações pertinentes a discussão proposta neste artigo, no que tange as representações acerca da interação dos surdos,

\begin{abstract}
A valorização da cultura ouvinte provoca um desconhecimento e desinteresse pelas angústias dos surdos quanto ao seu saber e a sua capacidade de aprender. $\mathrm{O}$ atraso escolar é uma realidade provocada pela falta de compreensão dos conteúdos. As pessoas que lidam diretamente com o surdo, tais como: os familiares e os professores, por décadas, desconheceram as especificidades próprias da comunidade.

Diante do exposto, surge um questionamento quanto à capacidade intelectual dos surdos. Ora, se o desenvolvimento cognitivo está atrelado à valorização da interação social entre sujeitos, com certeza ao surdo foi negado esse direito por décadas no nosso país.
\end{abstract}

Os estudos sistematizados e a observação dos dados coletados permitiram identificar que a educação de surdos perpassou momentos distintos e que as discussões ainda são divergentes e demandam muitos estudos e reflexões sobre o tema. Nesse mesmo contexto, situa-se a educação infantil, que, por muito tempo, foi considerada como uma etapa de "pré" algo, não tendo em seus objetivos caráter expressamente comprometido com o desenvolvimento das crianças menores.

Essas incertezas referem-se, inclusive, ao posicionamento perante a inclusão escolar e suas demandas, que refletem, de maneira nítida, a influência e as consequências dos embates ideológicos nas diferentes formas históricas da sociedade. Apresentam, com isso, reações que diferem das orientações contidas nos regimentos e direcionamentos legais, porém influenciadas de diferentes formas.

É possível afirmar, de acordo com a presente pesquisa, que os professores aqui apontados encontram-se um tanto quanto perdidos sobre a melhor forma de se pensar e protagonizar a educação de surdos, e, assim como ocorre em outras demandas, talvez seja algo ainda muito recente ${ }^{10}$, quando se considera a inclusão escolar das crianças surdas no ensino comum. Percebe-se ainda, nas entrevistas, que os professores desconhecem muitas das peculiaridades de um ensino pensado e planejado de forma bilíngue. Isso se dá porque eles não são também bilíngues, e ainda, muitas vezes, por não possuem o conhecimento de como deva ser esse ensino bilíngue ou ainda, as peculiaridades de se ensinar no caráter de segunda língua.

\footnotetext{
${ }^{10}$ Recentes no sentido de que os registros históricos e as legislações apontavam que esses alunos devessem ter um ensino segregado dos demais, em instituições especiais. O movimento de inclusão escolar toma força na década de 1980 nos países desenvolvidos e na década de 1990, nos demais países. Com isso, as escolas e as instituições de educação infantil foram sendo organizadas para receberem a matrícula dos alunos compreendidos como alunos com deficiência, dentre eles, as crianças surdas.
} 
Como já assinalado, a educação infantil é uma etapa singular da educação básica no que tange ao desenvolvimento da criança. Nesse sentido, frisa-se a importância da realização de um trabalho pedagógico com qualidade, pois esta será a etapa base para os futuros anos de escolarização e de vida dessas crianças. No caso dos alunos surdos, o acesso à língua de sinais, ou a falta desse acesso, poderá determinar muitas outras questões de desenvolvimento dessas.

\section{REFERÊNCIAS}

BRASIL. Lei n ${ }^{\circ}$ 10.436. Dispõe sobre a Língua Brasileira de Sinais - Libras e dá outras providências. Diário Oficial [da] República Federativa do Brasil. Brasília, DF, 24 abr. 2002.

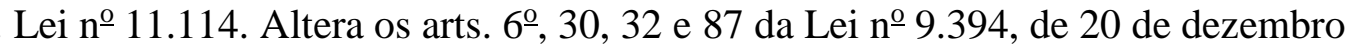
de 1996, com o objetivo de tornar obrigatório o início do ensino fundamental aos seis anos de idade. Diário Oficial [da] República Federativa do Brasil. Brasília, DF, 17 maio 2005 a.

Presidência da República. Casa Civil. Subchefia para Assuntos Jurídicos. Decreto $\mathrm{n}^{\circ}$ 5.626, de 22 de dezembro de 2005. Regulamenta a Lei $\mathrm{n}^{\circ} 10.436$, de 24 de abril de 2002, que dispõe sobre a Língua Brasileira de Sinais - Libras, e o art. 18 da Lei ${ }^{\circ} 10.098$, de 19 de dezembro de 2000. Brasília, 2005b. Disponível em:

<http://www.planalto.gov.br/ccivil_03/_ato2004-2006/2005/decreto/d5626.htm>. Acesso em: 13 set. 2013.

Ministério da Educação. Secretaria de Educação Continuada, Alfabetização, Diversidade e Inclusão. Relatório sobre a política linguística de educação bilíngue: língua brasileira de sinais e língua portuguesa. Brasília: MEC/SECADI, 2014.

BUENO, José Geraldo Silveira; MENDES, Geovana Mendonça Lunardi; SANTOS, Roseli Albino dos Santos (Orgs.). Deficiência e escolarização: novas perspectivas de análise. Araraquara: Junqueira \& Marin, 2008.

CAPELLINI, Vera Lúcia Messias Fialho. Infância e inclusão escolar de crianças com necessidades educacionais especiais. In: VICTOR, Sonia Lopes; DRAGO, Rogério; CHICON, José Francisco (Orgs.). Educação especial e educação inclusiva: conhecimentos, experiências e formação. Araraquara: Junqueira\&Marin, 2011.

DORZIAT, Ana; ARAÚJO, Joelma Remigio de; SOARES, Filippe Paulino. O direito dos surdos à educação: que educação é essa. In: DORZIAT, Ana (Org.). Estudos surdos: diferentes olhares. Porto Alegre: Mediação, 2011. p. 19-60.

DRAGO, Rogério. Inclusão na Educação Infantil. Rio de Janeiro: Wak, 2011.

FARIA, Evangelina Maria Brito de; ALVES, Edneia de Oliveira; BATISTA, Marie Gorett Dantas de A. e M.; MONTEIRO, Regina de Fátima F. V. Língua de sinais: um instrumento viabilizador do desenvolvimento cognitivo e interacional do surdo. In: DORZIAT, Ana (Org.). Estudos surdos: diferentes olhares. Porto Alegre: Mediação, 2011. p. 171- 208.

LACERDA Cristina Broglia Feitosa de; BERNARDINO, Bruna Mendes. O papel do intérprete de língua de sinais nas etapas iniciais de escolarização. In: LODI, Ana Claudia Balieiro; LACERDA, Cristina Broglia Feitosa de. Uma escola, duas línguas. Letramento em Língua portuguesa e língua de sinais nas etapas iniciais de escolarização. Porto Alegre. 2. ed. Mediação, 2010. p. 65-79. 
LACERDA, Cristina Broglia Feitosa de. O Intérprete de Língua Brasileira de Sinais (ILS). In: LODI, Ana Claudia Balieiro; MÉLO, Ana Dorziat Barbosa de; FERNANDES, Eulalia (Orgs.). Letramento, bilinguismo e educação de surdos. Porto Alegre: Mediação, 2012. p. 247- 287.

LACERDA, Cristina Broglia Feitosa de. Intérprete de Libras em atuação na Educação Infantil e no Ensino Fundamental. Porto Alegre: Mediação/FAPESP, 2009.

LIMA, Niédja Maria Ferreira de. Inclusão escolar de surdos: o dito e o feito. In: LODI, Ana Claudia Balieiro; MÉLO, Ana Dorziat Barbosa de; FERNANDES, Eulalia (Orgs.). Letramento, bilinguismo e educação de surdos. Porto Alegre: Mediação, 2012. p. 303-331.

LODI, Ana Claudia Balieiro; LUCIANO, Rosana de Toledo. Desenvolvimento da linguagem de crianças surdas em língua brasileira de sinais. In: LODI, Ana Claudia Balieiro; LACERDA, Cristina Broglia Feitosa de (Orgs.). Uma escola, duas línguas: letramento em língua portuguesa e língua de sinais nas etapas iniciais de escolarização. 2. ed. Porto Alegre: Mediação, 2010. p. 33-50.

MARQUES, Hivi de Castro Ruiz; BARROCO, Sonia Mari Shima; SILVA, Tânia dos Santos Alvarez da. O ensino da língua brasileira de sinais na educação infantil para crianças ouvintes e surdas: considerações com base na psicologia histórico-cultural. Rev. Bras. Ed. Esp., Marília, v. 19, n. 4, p. 503-518, out./dez. 2013.

MENDES, Enicéia Gonçalves. Inclusão marco zero: começando pelas creches. Araraquara: Junqueira \& Marin, 2010.

OLIVEIRA, Mércia Aparecida da Cunha. Práticas de professores do ensino regular com alunos surdos inseridos: entre a democratização do acesso e permanência qualificada e a reiteração da incapacidade de aprender. In: BUENO, José Geraldo Silveira; MENDES, Geovana Mendonça Lunardi; SANTOS, Roseli Albino dos Santos (Orgs.). Deficiência e escolarização: novas perspectivas de análise. Araraquara: Junqueira \& Marin, 2008. p. 163- 204.

QUADROS, Ronice Müller de. Aquisição da linguagem por crianças surdas. In: BRASIL. Ministério da Educação. Programa de capacitação de recursos humanos do Ensino Fundamental: língua brasileira de sinais. Brasília: SEESP, 1998. v. 3.

RABELO, Lucélia Cardoso Cavalcante. Deficiência, estigma e preconceito: há uma inclusão possível na sociedade atual? In: DENARI, Fátima Elisabeth (Org.) Contrapontos da Educação Especial. São Carlos: Pedro \& João Editores, 2012. p. 239-249.

Recebido 17/04/2015

Aprovado 11/2016 